\title{
Optimal Control for a Tuberculosis Model with Exogenous Reinfection under the Influence of Stigma
}

\author{
Remilou Liguarda ${ }^{1}$, Wolfgang Bock ${ }^{2}$, and Randy Caga-anan ${ }^{1}$ \\ ${ }^{1}$ Mindanao State University - Iligan Institute of Technology \\ ${ }^{2}$ Technische Universität Kaiserslautern
}

February 4, 2022

\begin{abstract}
Often described as the world's most deadly infectious disease, Tuberculosis remains a serious health threat in many parts of the world, especially in the developing countries. One of the social barriers hindering TB patients to seek and complete medical attention is stigmatization. In this study, we incorporated stigmatization on a model published by Feng et al. last 2000 . We obtained the basic reproduction number and showed conditions where multiple endemic equilibrium will exist depending on a reinfection threshold. The model predicted a significant increase in the basic reproduction number as the level of stigmatization increases. We used optimal control theory to investigate the effect of controls to combat stigmatization and compare these controls with the usual controls such as improving treatment and minimizing reinfection. Simulations show that although stigmatization controls are helpful, they are not enough to successfully control the disease. A combination of all the controls will be ideal and some optimal rates of doing it over time are given, depending on the perceived cost of implementation.
\end{abstract}

\section{Hosted file}

Final_Paper-2.pdf available at https://authorea.com/users/458866/articles/555319-optimalcontrol-for-a-tuberculosis-model-with-exogenous-reinfection-under-the-influence-ofstigma 